\title{
Catalysts based in cerium oxide for wet oxidation of acrylic acid in the prevention of environmental risks
}

\author{
Adrián M.T. Silva, Rita R.N. Marques, Rosa M. Quinta-Ferreira* \\ Department of Chemical Engineering, University of Coimbra, Polo II-Pinhal de Marrocos, 3030-290 Coimbra, Portugal
}

Received 30 April 2003; received in revised form 2 August 2003; accepted 10 September 2003

\begin{abstract}
Acrylic acid is a refractory compound for the non-catalytic wet oxidation (WO) process and can seriously damage the environment when released in industrial effluents. Oxidation of acrylic acid by catalytic wet oxidation (CWO) was studied in slurry conditions in a high-pressure batch reactor at $200^{\circ} \mathrm{C}$ and 15 bar of oxygen partial pressure. Several solid cerium-based catalysts prepared in our laboratory were used $(\mathrm{Ag} / \mathrm{Ce}, \mathrm{Co} / \mathrm{Ce}, \mathrm{Mn} / \mathrm{Ce}, \mathrm{CeO}, \mathrm{MnO})$ and evaluated in terms of activity, selectivity and stability. $\mathrm{Mn} / \mathrm{Ce}$ shows the higher activity in $2 \mathrm{~h}$ with 97.7\% reduction of total organic carbon (TOC) followed by: $\mathrm{MnO}(95.5 \%)>\mathrm{Ag} / \mathrm{Ce}(85.0 \%)>\mathrm{Co} / \mathrm{Ce}(65.1 \%)>\mathrm{CeO}(61.2 \%)$. Attempts were also carried out to analyze the influence of different $\mathrm{Mn} / \mathrm{Ce}$ molar ratios. High percentages of Mn lead to practically total organic carbon concentration (TOC) abatements while low ratios lead to the formation of non-oxidizable compounds. Acrylic acid was readily degraded by all the catalysts pointing out the high importance of using a catalytic process. $\mathrm{pH}$ was an indicator of the reaction pathway and acetic acid was found as the major reaction intermediate compound; however it is completely oxidized after $2 \mathrm{~h}$ with exception for $\mathrm{Co} / \mathrm{Ce}, \mathrm{CeO}$ and $\mathrm{MnO}$. Carbon adsorption and leaching of metals were poorly found for $\mathrm{Mn} / \mathrm{Ce}$ indicating high stability. The catalyst microstructure after the reaction was analyzed and formation of whiskers of $\beta-\mathrm{MnO}_{2}$ (or less probably $\mathrm{MnOOH}$ ) were observed at the catalyst surface. Therefore, $\mathrm{Mn} / \mathrm{Ce}$ revealed to be a promising catalyst for the treatment of effluents containing acrylic acid; nevertheless, its commercialization depends on further research.
\end{abstract}

(C) 2003 Elsevier B.V. All rights reserved.

Keywords: Environment; Pollution; Acrylic acid effluents; Wet oxidation; Catalysts; Manganese; Cerium

\section{Introduction}

The wet oxidation (WO) process has been earning an important industrial role nowadays in different chemical companies for the treatment of toxic effluents $[1,2]$. However, short chains carboxylic acids have been found as refractory compounds for this technology [3]. In particular, acrylic acid $\left(\mathrm{C}_{3} \mathrm{H}_{4} \mathrm{O}_{2}\right)$ is thermally stable up to high temperatures $\left(280^{\circ} \mathrm{C}\right)$ and in terms of total organic carbon concentration (TOC) is poorly oxidized below $250^{\circ} \mathrm{C}$ [4]. For this reason, the oxidation of this compound is a rate controlling step in the complete TOC degradation of different pollutant solutions [3]. Acrylic acid is widely used in several industries (painting, chemical fibers, adhesives, paper, oil additives, detergents) and when released in effluents serious damage

\footnotetext{
* Corresponding author. Tel.: +351-239-798-723; fax: +351-239-798-703.

E-mail addresses: adrian3@eq.uc.pt (A.M.T. Silva),rosa@eq.up.pt (R.M. Quinta-Ferreira).
}

to the environment can be caused due to its high toxicity for aquatic organisms [5].

Catalysis research is a key factor in the development of the WO environmental technology, aiming pollutant abatements under milder operating conditions. However, few attempts have been carried out in literature for the catalytic oxidation of acrylic acid. The catalysts used in WO can be generally divided into three categories: (1) oxides of the transition metals, (2) supported noble metals and (3) metal salts and their complexes. The homogeneous catalysts are normally avoided since due to their toxic contamination they should be removed from the solution in a second treatment step. Heterogeneous catalysts applications based in noble metals (Pt, $\mathrm{Ru}, \mathrm{Pd}, \mathrm{Rh}, \mathrm{Ir}, \mathrm{Ag}$ ) and oxides metals ( $\mathrm{Mn}, \mathrm{Co}, \mathrm{Cu}, \mathrm{Zn}, \mathrm{V}$, $\mathrm{Ni}, \mathrm{Fe}, \mathrm{Bi}, \mathrm{Ti})$ using different supports $\left(\mathrm{Al}_{2} \mathrm{O}_{3}, \mathrm{CeO}_{2}, \mathrm{TiO}_{2}\right.$, $\mathrm{ZrO}_{2}, \mathrm{NaY}$ zeolite) are summarized in different review papers $[1,3,6,7]$. Regarding the heterogeneous catalysts, both categories present advantages and drawbacks. Noble metals are expensive components increasing considerably the process cost. On the other hand, oxides of the transition metals 
have been found in some cases as unstable due to deactivation by leaching of the metals to the liquid phase, fouling of surface and adsorption of carbonyl compounds by the catalyst [6]. In this context, it is quite important to develop economical, active and stable catalysts that can be effective for degradation of organic compounds by WO.

Olivero et al. [8] studied the oxidation of acrylic acid under Ru noble metal catalysts based in carbon, cerium and carbon-cerium. They concluded that both supports containing carbon do not provide a high activity to the catalyst (less than $40 \%$ of acrylic acid conversion), while a total oxidation is obtained using $\mathrm{Ru} / \mathrm{Ce}$. However $\mathrm{Ru}$ is an expensive material and it is our goal to find out more economic catalysts. Since cerium is considered as a promoter active support, different cerium-based catalysts were selected in the present work $(\mathrm{Mn} / \mathrm{Ce}, \mathrm{Ag} / \mathrm{Ce}, \mathrm{Co} / \mathrm{Ce})$. These catalysts were selected taking into account their activity in the oxidation of other compounds such as acetic acid [3], formaldehyde [9], phenol [10] and ammonia [11]. In the oxidation of polyethylene glycol (PEG-200) Ru/Ce showed higher activity than $\mathrm{Mn} / \mathrm{Ce}$ using the same reaction conditions; however, it is also reported that acetic acid was not degraded totally with $\mathrm{Ru} / \mathrm{Ce}$ while complete removal was obtained with $\mathrm{Mn} / \mathrm{Ce}$ [7]. Therefore, as referred, the $\mathrm{Ru} / \mathrm{Ce}$ catalyst presented selectivity toward specific substances. Since $\mathrm{Mn} / \mathrm{Ce}$ is an economical catalyst with high activity in the oxidation of a wide range of compounds [3,6,9] and it is most active than $\mathrm{Ru} / \mathrm{CeO}_{2}$ in the oxidation of acetic acid, which is expected as intermediary compound of the reaction, $\mathrm{Mn} / \mathrm{Ce}$ was selected for this work and its activity was compared with $\mathrm{Ag} / \mathrm{Ce}$ and $\mathrm{Co} / \mathrm{Ce}$. The most effective catalyst $(\mathrm{Mn} / \mathrm{Ce})$ was evaluated under different molar ratios of the respective metal. Experiments were also carried out with both pure oxide metals ( $\mathrm{MnO}$ and $\mathrm{CeO}$ ) in order to understand the effect of these metals in the $\mathrm{Mn} / \mathrm{Ce}$ composite oxide.

\section{Experimental}

\subsection{Material, catalysts and equipment}

Acrylic acid (2-Propenoic acid- $\mathrm{C}_{3} \mathrm{H}_{4} \mathrm{O}_{2}$ ) $99.5 \%$ stabilized with 180 to $220 \mathrm{ppm}$ of hydroquinone monomethyl ether (4-methoxyphenol-MEHQ- $\mathrm{C}_{7} \mathrm{H}_{8} \mathrm{O}_{2}$ ) was obtained from Acros organics. $\mathrm{Mn} / \mathrm{Ce}, \mathrm{Co} / \mathrm{Ce}, \mathrm{Ag} / \mathrm{Ce}, \mathrm{MnO}$ and $\mathrm{CeO}$ catalysts were prepared in our laboratory by precipitation according the procedures described elsewhere [9] and using the corresponding metal nitrates as precursors (Riedel-de-Häen and Labsolve). The molar composition ratios for $\mathrm{Co} / \mathrm{Ce}$ and $\mathrm{Ag} / \mathrm{Ce}$ was $70 / 30$ and for $\mathrm{Mn} / \mathrm{Ce} 70 / 30$ and $22 / 78 . \mathrm{Mn} / \mathrm{Ce}, \mathrm{Co} / \mathrm{Ce}, \mathrm{MnO}$ and $\mathrm{CeO}$ were prepared with a mixed aqueous solution of metal salts $(15 \mathrm{~g}$ of metal salt/100 ml), poured into $200 \mathrm{ml}$ of a $3 \mathrm{M} \mathrm{NaOH}$ solution. The precipitate was filtrated, washed five times with $500 \mathrm{ml}$ of ultra pure water and dried at $100{ }^{\circ} \mathrm{C}$ over night, followed by calcination at $350^{\circ} \mathrm{C}$ for $\mathrm{Co} / \mathrm{Ce}$ and $300^{\circ} \mathrm{C}$ for $\mathrm{Mn} / \mathrm{Ce}$, $\mathrm{Co} / \mathrm{Ce}, \mathrm{MnO}$ and $\mathrm{CeO}$ catalysts. An aqueous solution of silver nitrate and cerium nitrate was used to prepare the $\mathrm{Ag} / \mathrm{Ce}$ catalyst. An $\mathrm{NaOH} 3 \mathrm{M}$ solution, prepared from a sodium hydroxide salt (Merck), was added until a pH equal to 10 was achieved. The precipitate was filtrated, washed three times with ultra pure water and dried over night at $100^{\circ} \mathrm{C}$, followed by calcination at $300^{\circ} \mathrm{C}$. The catalysts were crushed in order to obtain a fine power with particle sizes mainly in the range $125-841 \mu \mathrm{m}$; this range was previously tested as appropriate to ensure the elimination of internal diffusion resistances.

The oxidation process was studied in a laboratorial unit with a high-pressure 11 autoclave of 316 stainless steel (Parr-model 4531M) described elsewhere [9]. The autoclave was initially charged with $450 \mathrm{ml}$ of deionized water and preheated up to $200 \pm 1{ }^{\circ} \mathrm{C}$. As soon as this temperature was attained, $50 \mathrm{ml}$ of a pre-calculated acrylic acid solution was injected in order to attain a concentration of $1000 \mathrm{ppm}$ (500 ppm in terms of TOC) in the reactor. High purity oxygen (99.999\%) was then introduced and this was taken as the "zero" time for reaction. All catalytic experiments were carried out in slurry conditions with $3 \mathrm{~g}$ of powder catalyst $(6.0 \mathrm{~g} / \mathrm{l})$, oxygen partial pressure of $15.0 \pm 0.3 \mathrm{bar}$ and $350 \pm 3 \mathrm{rpm}$ agitation velocity.

\subsection{Analytical techniques}

The samples withdrawn periodically from the reactor were analyzed for $\mathrm{pH}$ and TOC concentration in a Shimadzu 5000 TOC Analyzer, which operates based on the combustion/non-dispersive infrared gas analysis method. The carboxylic acids concentrations were determined by high performance liquid chromatography (HPLC-Knauer system), equipped with an UV detector (set at $209 \mathrm{~nm}$ ) and a SS-Column of $300 \times 8 \mathrm{~mm}$ internal diameter and $10 \mu \mathrm{m}$ particle size, which consists of a sulfonated cross-linked styrene-divinylbenzene copolymer as a stationary phase (Eurokat H). The column was set at $25^{\circ} \mathrm{C}$ and a mobile phase of $0.01 \mathrm{~N} \mathrm{H}_{2} \mathrm{SO}_{4}$ with a flow rate of $1 \mathrm{ml} / \mathrm{min}$ was used. Leaching of manganese was determined by atomic absorption (Spectrometer Perkin Elmer-3300). In the end of the experiment the catalyst was recovered in order to evaluate the carbon concentration on the solid by means of elemental analysis (Finsons Instruments EA 1108 CHNS-O). Catalyst texture and morphology were examined at different scales/magnifications by scanning electron microscopy (SEM) on a JEOL JSM-5310 scanning microspore and by transmission electron microscopy (TEM). For the TEM analysis the samples were prepared by suspending the powder in ethanol and pouring the solution into holy carbon coated copper grids. Analysis were carried out at an operating voltage of $200 \mathrm{kV}$ in a Jeol $2000 \mathrm{FX}$ transmission electron microspore equipped with a Link AN 10000 EDXS (energy-dispersive X-ray spectroscopy) system with a UTW $\mathrm{Si}$ (Li) detector. 


\section{Results and discussion}

\subsection{Catalytic activity of different cerium-based catalysts}

The results of our study are shown in Fig. 1(a-f) where TOC reduction, $\mathrm{pH}$ profiles and intermediate compounds are represented. The catalyst efficiency was measured taking into account the TOC concentration of the solution as principal parameter, since besides acrylic acid degradation it is important to guarantee the conversion of the overall organic carbon in solution to carbon dioxide and water. Fig. 1(a) represents the TOC reduction for the non-catalytic wet oxidation as well as for the catalytic process when using different cerium-based catalysts at constant molar ratio of 70/30. While acrylic acid solutions can not be oxidized in terms of TOC without the use of a catalyst, cerium-based catalysts showed significant activities and high conversions. The cerium support $(\mathrm{CeO})$ also revealed catalytic properties leading to a final reduction of $61.2 \%$. Activity of $\mathrm{CeO}$ was also reported by Imamura et al. [12] in the oxidation of a model wastewater referring that such activity can be due to the mobility of the surface oxygen. Combining cerium oxide with $\mathrm{Co}, \mathrm{Ag}$ or $\mathrm{Mn}$, the efficiency of the oxidation process in $2 \mathrm{~h}$ increased by the following order: $\mathrm{Co} / \mathrm{Ce} 70 / 30(65.1 \%)<$ $\mathrm{Ag} / \mathrm{Ce} 70 / 30(85.0 \%)<\mathrm{Mn} / \mathrm{Ce} 70 / 30(97.7 \%)$. Therefore, $\mathrm{Mn}$ showed to be the best metal to be combined with $\mathrm{Ce}$ in terms of catalytic activity. The catalyst $\mathrm{Mn} / \mathrm{Ce} 70 / 30$ showed high efficiency and high reaction rate that made possible to obtain $94.1 \%$ of TOC reduction in the first $30 \mathrm{~min}$ and 97.7\% after $1 \mathrm{~h}$. Using $\mathrm{Ag} / \mathrm{Ce} 70 / 30$ the TOC reduction increased also significantly until $80.9 \%$ in the first $30 \mathrm{~min}$; however, the subsequent plateau in $85.0 \%$ revealed the possible formation of refractory compounds which were not able to be decomposed. The Co metal does not improve significantly the activity of $\mathrm{CeO}$. This can also be observed in Fig. 1(b) where the increment in TOC removal by adding a transition metal $(\mathrm{Mn}, \mathrm{Ag}$ or $\mathrm{Co}$ ) to $\mathrm{CeO}$ is represented. After $75 \mathrm{~min}$ the influence of the Co content is negligible and the maximum effect is observed at $15 \mathrm{~min}$ where the efficiency of $\mathrm{Co} / \mathrm{Ce} 70 / 30$ is $25 \%$ higher than the one related to $\mathrm{CeO}$. For all the catalysts the maximum value of the efficiency increment was obtained in the range of 15-30 min, namely $50.0 \%$ for $\mathrm{Ag} / \mathrm{Ce} 70 / 30$ and $62.4 \%$ for $\mathrm{Mn} / \mathrm{Ce} 70 / 30$. Therefore, the improvement on the activity of $\mathrm{Ce}$ by $\mathrm{Co}, \mathrm{Ag}$ and $\mathrm{Mn}$ is more important in the initial reaction times with better results to $\mathrm{Mn}$. In a recent paper [9] dedicated to the oxidation of formaldehyde solutions stabilized in methanol, our results also revealed that $\mathrm{Mn} / \mathrm{Ce}$ showed higher activity than $\mathrm{Ag} / \mathrm{Ce}$ and $\mathrm{Co} / \mathrm{Ce}$, being possible to obtain practically the complete oxidation in terms of TOC for $\mathrm{Mn} / \mathrm{Ce}$. Therefore, these potential results obtained for aldehyde and alcohol oxidation are emphasized with the present study regarding the effectiveness of the $\mathrm{Mn} / \mathrm{Ce}$ catalyst extended to unsaturated carboxylic acids.

\subsection{Effect of Ce and Mn on the catalytic activity of $\mathrm{Mn} / \mathrm{Ce}$}

Fig. 1(c) shows that higher TOC reductions were obtained in $2 \mathrm{~h}$ with $\mathrm{Mn} / \mathrm{Ce} 70 / 30$ (97.7\%) than with $\mathrm{Mn} / \mathrm{Ce}$ 22/78 (87.0\%); however the initial rates (first $20 \mathrm{~min}$ ) are not significantly affected by the molar ratio of manganese and cerium. In both cases an asymptotic value in TOC reduction was observed approximately after $30 \mathrm{~min}$ of reaction. However, for the $\mathrm{Mn} / \mathrm{Ce} 70 / 30$ such plateau corresponds to a practically total reduction while for $\mathrm{Mn} / \mathrm{Ce} 22 / 78$ a high content of TOC is still not oxidized. In fact, a significant fraction of refractory compounds representing $13 \%$ of the initial TOC concentration was not suitable to be oxidized by the low-manganese catalyst. The effect of the Mn content in TOC reduction for different reaction times is also highlighted in Fig. 2 where it is shown that even if the combination of Mn with Ce revealed a higher effect in the initial times of the oxidation process, for longer periods the effect of $\mathrm{Mn}$ is also beneficial. The interaction between the two components of the $\mathrm{Mn} / \mathrm{Ce}$ catalyst was carefully characterized by Chen et al. [13]. According to these authors the active sites should be considered as two groups: one related to the higher oxidation state of manganese oxide species and another based on the lower oxidation state of manganese with catalytic properties fomented by the effect of $\mathrm{Ce}^{4+}$. In pure manganese oxide three possible high oxidation states are found $+2,+3$ and +4 , which confers high activity to $\mathrm{MnO}$. When cerium is added, the surface of manganese seemed to be different with lower oxidation states. However, it is known that if manganese is added to cerium, the concentration of $\mathrm{Ce}^{4+}$ increases in detriment of $\mathrm{Ce}^{3+}$ and the electrons of the higher state of cerium seem to be transferred to $\mathrm{Mn}$ [13]. Therefore, the high activity of $\mathrm{Mn} / \mathrm{Ce} 70 / 30$ can be explained by an efficient equilibrium of the electrons transfer, while in the $\mathrm{Mn} / \mathrm{Ce} 22 / 78$ the low content in manganese do not promote the increase of $\mathrm{Ce}^{4+}$ species, decreasing then the catalytic activity.

Using the catalyst based only in the transition metal $(\mathrm{MnO})$ a final TOC reduction of $95.5 \%$ is reached which is similar with the one related to $\mathrm{Mn} / \mathrm{Ce} 70 / 30(97.7 \%)$ and higher than for $\mathrm{Mn} / \mathrm{Ce} 22 / 78$ (87.0\%). Therefore, the final high TOC abatement with $\mathrm{Mn} / \mathrm{Ce}$ seems to be due to the effect of the manganese oxide. However, the reaction for $\mathrm{MnO}$ is significantly slower than when a $\mathrm{Mn} / \mathrm{Ce}$ composite is used; in fact, one can observe in Fig. 1(c) that in $30 \mathrm{~min}$ a reduction of $94.1 \%$ is obtained for $\mathrm{Mn} / \mathrm{Ce} 70 / 30$ against the lower value $(45.2 \%)$ related to $\mathrm{MnO}$. Cerium can then improve the catalytic activity of the manganese transition metal oxide in a significant way. This is in accordance with the results of Chen et al. [13], since although the higher oxidation states of manganese are related to $\mathrm{MnO}$, the global efficiency is due to two different groups of activation sites which are believed to exist in $\mathrm{Mn} / \mathrm{Ce} 70 / 30$. The results obtained for oxidation of acrylic acid are in agreement with the literature since Imamura et al. [11] in studies with $\mathrm{Mn} / \mathrm{Ce}$ for 

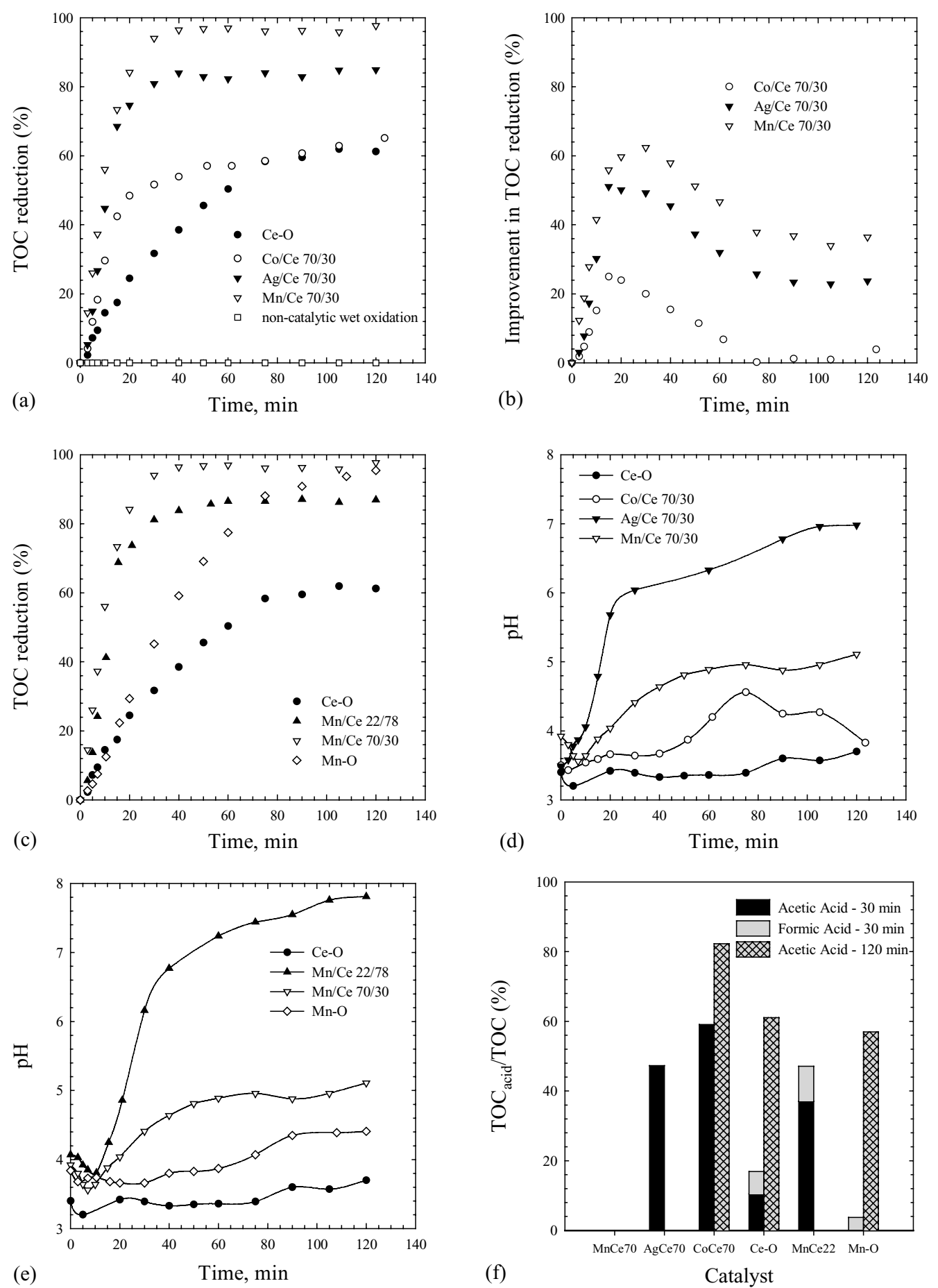

Fig. 1. (a) TOC reduction as a function of time for non-catalytic wet oxidation and different cerium-based catalysts; (b) Increment in TOC reduction of cerium-based catalysts in relation to pure cerium oxide (CeO); (c) TOC reduction as a function of time for different $\mathrm{Ce}$ and $\mathrm{Mn}$ catalysts; (d) pH profiles of the solution for different cerium-based catalysts; (e) $\mathrm{pH}$ profiles of the solution for different $\mathrm{Ce}$ and $\mathrm{Mn}$ catalysts; (f) Acetic and formic acid percentages in terms of TOC for different catalysts after $30 \mathrm{~min}$ and $120 \mathrm{~min}$ of reaction; $\left(200^{\circ} \mathrm{C}, 15 \mathrm{bar}\right.$ oxygen partial pressure and $6 \mathrm{~g} / \mathrm{l}$ catalyst concentration).

oxidation of ammonia concluded that $\mathrm{Mn} / \mathrm{Ce}$ with a mol.\% of 70/30 was more active than using other ratios. Imamura et al. [14] found for polyethylene glycol the maximum in a mol.\% of 40/60. Chen et al. [13] for the oxidation of phenol found as the most active catalyst $\mathrm{Mn} / \mathrm{Ce} 60 / 40$. Silva et al. [9] in the oxidation of formaldehyde point an optimal range of $\mathrm{Mn}$ content of $70-80 \%$. The optimal ratio for all the compounds seems to occur in the 40/60-80/20 window.

Therefore, manganese has a crucial role in the high TOC abatement and the combination with cerium will increase 


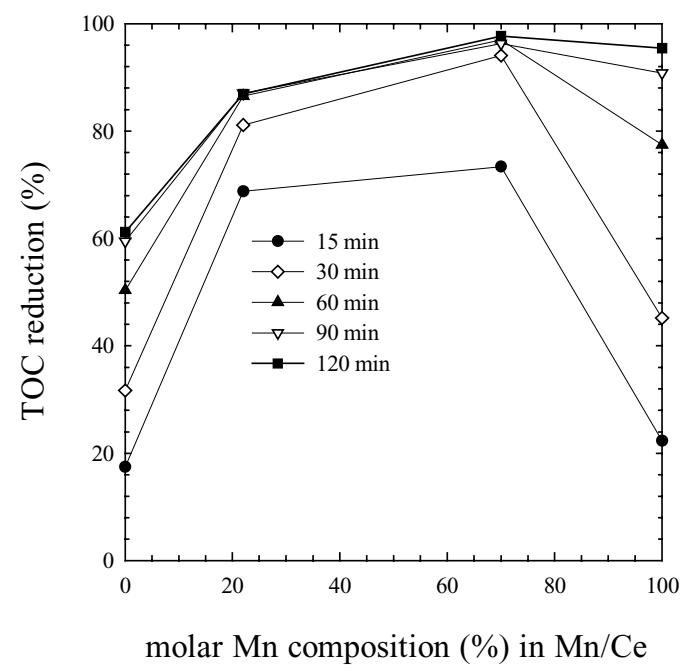

Fig. 2. TOC reduction as a function of the molar Mn composition in the $\mathrm{Mn} / \mathrm{Ce}$ catalysts for different reaction times $\left(200^{\circ} \mathrm{C}, 15\right.$ bar oxygen partial pressure and $6 \mathrm{~g} / \mathrm{l}$ catalyst concentration).

significantly the initial reaction rate. However, high percentages of cerium can also have some undesired influence in the final TOC reduction after $2 \mathrm{~h}$ when $\mathrm{Mn} / \mathrm{Ce} 22 / 78$ is less active than $\mathrm{MnO}$. Finally with $\mathrm{Mn} / \mathrm{Ce} 70 / 30$ it is possible to combine both wanted effects: high TOC reduction as well as high initial reaction rates.

\section{3. $p H$ evaluation}

The change in the $\mathrm{pH}$ of solutions submitted to the oxidation treatment is an indicator of how the reaction proceeds [15]; the evolution of $\mathrm{pH}$ was then investigated and the results are shown in Fig. 1(d) and (e), which are related to the experiments represented in Fig. 1(a) and (c) respectively. In general these $\mathrm{pH}$ values show the same trends that have been typically found in CWO $[15,16]$ : a slight decrease in the first minutes followed by a subsequent increase. These trends were only different for $\mathrm{Ag} / \mathrm{Ce}$ and $\mathrm{Co} / \mathrm{Ce}$ (Fig. 1(d)); in the first case the initial decrease was not observed and in the second one a final decrease after $75 \mathrm{~min}$ was detected. For $\mathrm{Co} / \mathrm{Ce}$ this decrease seems to be related with the slight increase in the TOC reduction observed in Fig. 1(a) for the same reaction time. For $\mathrm{Ag} / \mathrm{Ce}$ the initial high increase in TOC reduction was followed by a high increase in $\mathrm{pH}$ (which may be due to the formation of carbon dioxide and water) and after $30 \mathrm{~min}$, when the TOC reduction reached a plateau, the $\mathrm{pH}$ increased slowly. Moreover, the formation of a precipitate with time was observed in the samples that were withdrawn from the reactor. Therefore, this catalyst is not recommended for the process since the formation of this precipitate will originate another contamination source.

For the Mn/Ce catalysts (Fig. 1(e)) a rapid decrease seems to indicate the formation of low weight carboxylic acids that may be potential intermediates products of the reac- tion. However, the further increase observed mainly for the $\mathrm{Mn} / \mathrm{Ce} 22 / 78$ catalyst should be due to the formation of carbon dioxide and water. For both monometallic catalysts $(\mathrm{MnO}$ and $\mathrm{CeO}$ ) the $\mathrm{pH}$ does not change drastically probably due to its slower reaction rate.

\subsection{Pathway mechanistic interpretation}

In order to draft a mechanistic pathway of the reaction, the conversion from acrylic acid into intermediates compounds in the liquid phase was evaluated during the course of the oxidation reaction. Regarding acrylic acid it was found that this compound is rapidly oxidized by all the catalysts while its degradation was not possible when submitted to the non-catalytic wet oxidation at $200^{\circ} \mathrm{C}$. Therefore, the use of a catalyst is strongly necessary in the oxidation of acrylic acid. It is our objective to obtain a catalyst able to reduce the TOC concentrations as much as possible with the aim to purify at the maximum level the effluents containing acrylic acid. In this context the contribution for the total TOC of remaining chemical compounds was evaluated. After $30 \mathrm{~min}$ of reaction the ratio between the TOC associated to acetic and formic acids $\left(\mathrm{TOC}_{\mathrm{acid}}\right)$ and the global TOC are represented in Fig. 1(f). These results show that acetic acid is an important reaction intermediate. It was not detected for $\mathrm{Mn} / \mathrm{Ce} 70 / 30$, probably due to the fact that at $30 \mathrm{~min}$ it had already been oxidized since at this time only $5.9 \%$ of the initial TOC is found in solution. For $\mathrm{MnO}$ acetic acid was also not detected being formed only formic acid. For $\mathrm{CeO}$ and $\mathrm{Mn} / \mathrm{Ce} 22 / 78$ formic acid was detected with considerably lower percentages than those of acetic acid. After $120 \mathrm{~min}$ these catalysts are able to oxidize totally the formic acid. Also acetic acid was completely degraded for $\mathrm{Mn} / \mathrm{Ce}$ and $\mathrm{Ag} / \mathrm{Ce}$ catalysts, while significant contents were found for $\mathrm{CeO}(61.1 \%$ of TOC), $\mathrm{Co} / \mathrm{Ce}(82.3 \%$ of $\mathrm{TOC})$ and $\mathrm{MnO}$ (57.0\% of TOC).

Therefore, these results point out that: (1) Mn/Ce 70/30 is able to reduce readily all the carbonyl compounds; (2) the reaction of $\mathrm{Mn} / \mathrm{Ce} 22 / 78$ and $\mathrm{CeO}$ seems to have initially the same mechanistic pathway, with formation of acetic and formic acid; however the presence of manganese makes possible the subsequent total degradation of both acids. Also $\mathrm{Ag} / \mathrm{Ce} 70 / 30$ is able to decompose the acetic acid initially formed; (3) the non-oxidizable TOC concentration observed for $\mathrm{Mn} / \mathrm{Ce} 22 / 78$ in Fig. 1(c) and for Ag/Ce 70/30 in Fig. 1(a) is not due to acetic and formic acids but probably to other carbonyl species resulting from the acetic acid oxidation which were not identified. In fact, acetic acid is detected at $30 \mathrm{~min}$ of the reaction time and not observed at $120 \mathrm{~min}$ (Fig. 1(f)), whereas the global TOC remains approximately constant during this time period; (4) $\mathrm{Co} / \mathrm{Ce}$ and $\mathrm{CeO}$ are catalysts with low activity since an increase in the percentage of acetic acid was observed in the final times of the oxidation reactions; (5) in the case of $\mathrm{MnO}$ a low percentage of TOC was in the solution after $2 \mathrm{~h}$ (Fig. 1(c)), mainly due to acetic acid (Fig. 1(f)), which strengthens the con- 
clusion that the combination of cerium with manganese is preferable for oxidation of acetic acid than the use of the isolated metals.

Comparing the activity of the $\mathrm{Ru} / \mathrm{Ce}$ catalyst used by Olivero et al. [8] with the results obtained in this work with $\mathrm{Mn} / \mathrm{Ce}$, it is important to highlight that in both cases acetic acid is a reaction intermediate compound. Those authors concluded that acetic acid was not oxidizable in their experiments. Imamura et al. [17] refer that at $200^{\circ} \mathrm{C}$ acetic acid is $44.5 \%$ removed with $\mathrm{Ru} / \mathrm{Ce}$ while complete degradation is obtained with a $\mathrm{Mn} / \mathrm{Ce}$ catalyst under the same reaction conditions, pointing out $\mathrm{Mn} / \mathrm{Ce}$ as more selective for acetic acid degradation than $\mathrm{Ru} / \mathrm{Ce}$. Therefore, these results in addition to the ones achieved in our work reveal the high activity of $\mathrm{Mn} / \mathrm{Ce}$ and reinforce that $\mathrm{Mn} / \mathrm{Ce}$ is preferable to $\mathrm{Ru} / \mathrm{Ce}$ in the treatment of wastewaters containing acrylic acid having also in mind the high cost of noble metals.

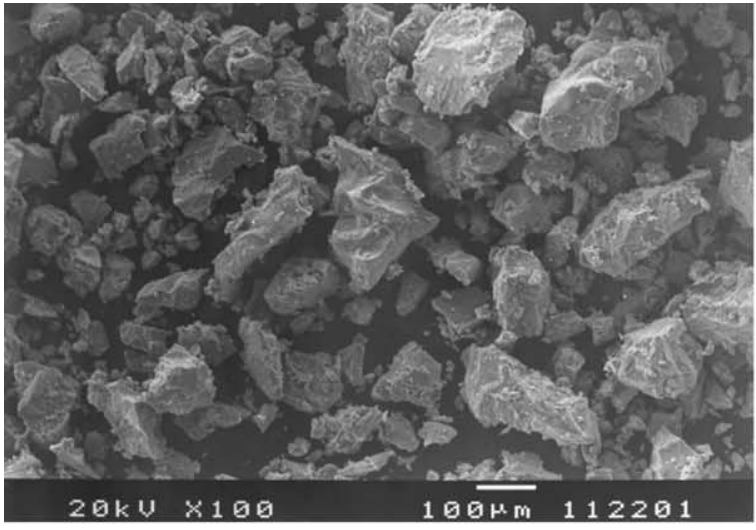

3(a-1)

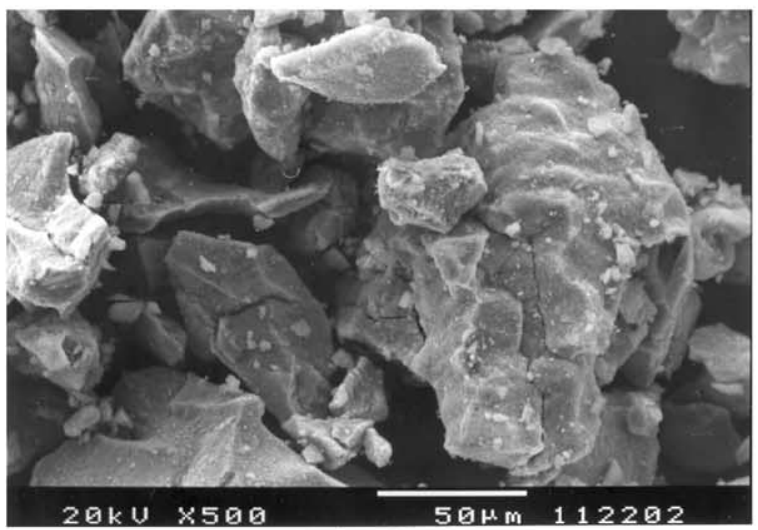

$3(a-2)$

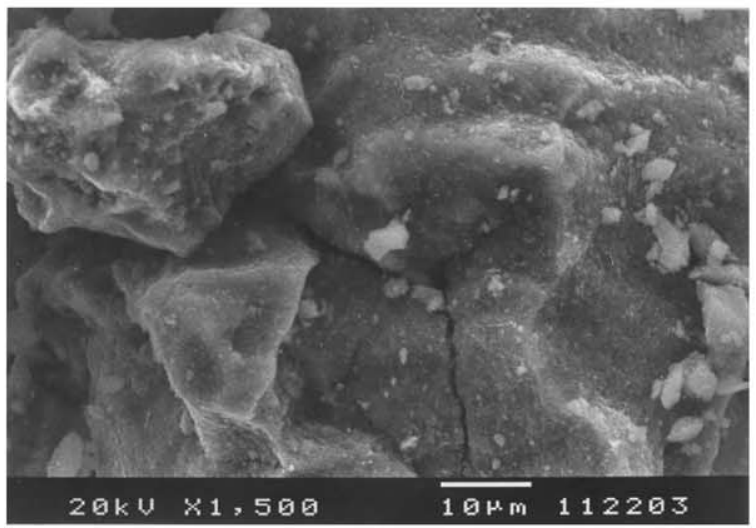

$3(a-3)$

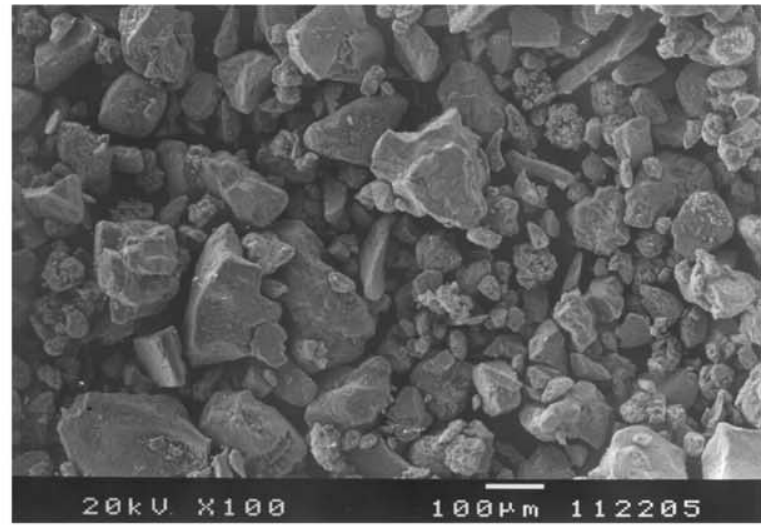

3(b-1)

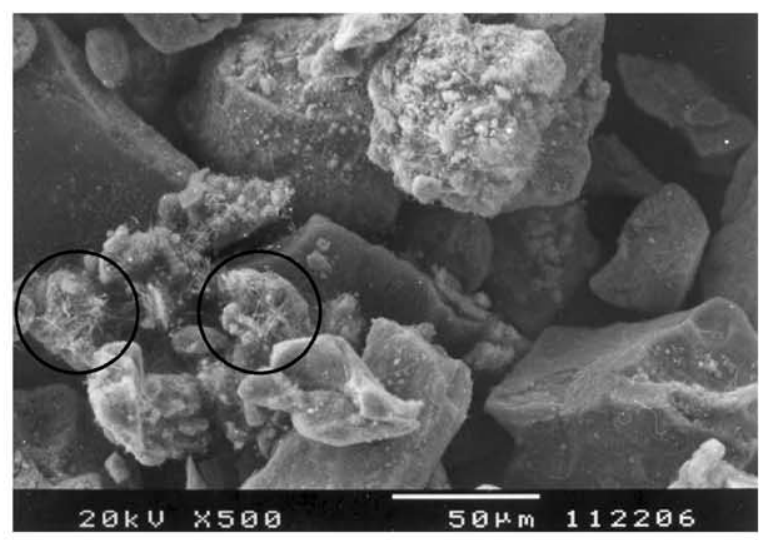

$3(b-2)$

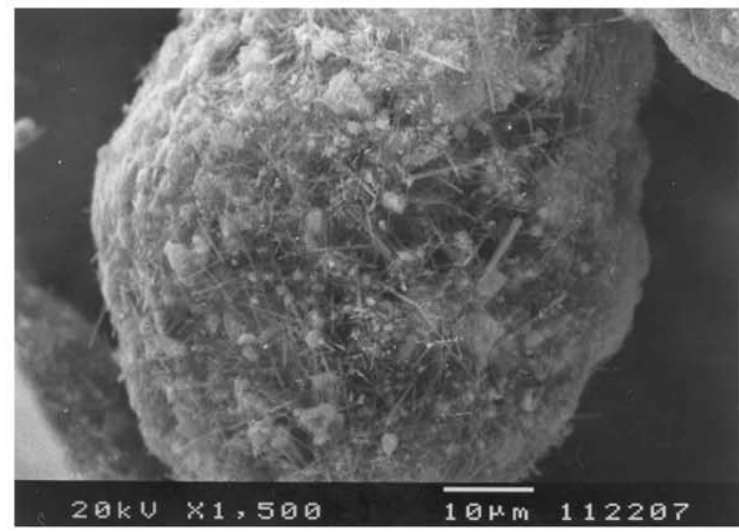

3(b-3)

Fig. 3. SEM photographs showing different scales/magnifications: (a) fresh $\mathrm{Mn} / \mathrm{Ce} 70 / 30$; (b) used Mn/Ce 70/30 catalyst: (1) 100×; (2) 500×; (3) 1500×; (4) $3500 \times$; (5) $20,000 \times$ 


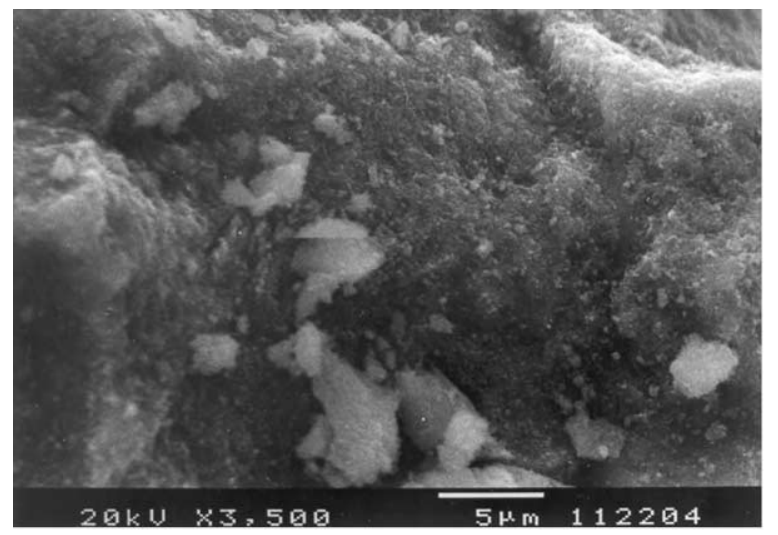

$3(a-4)$

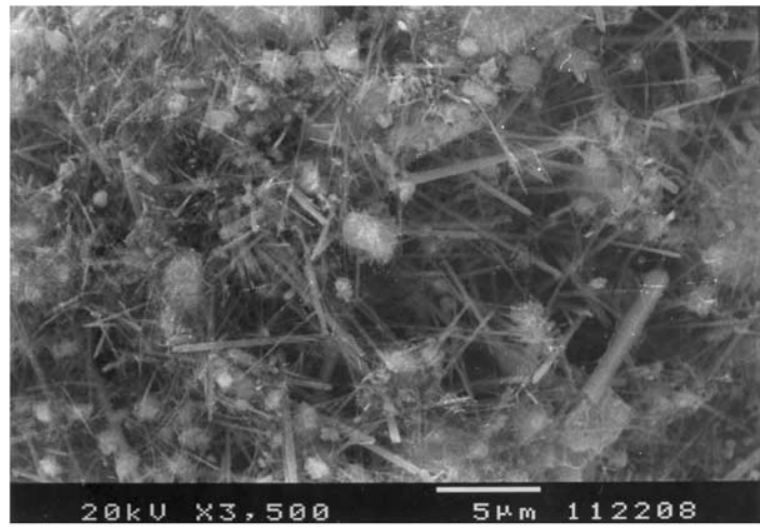

$3(b-4)$

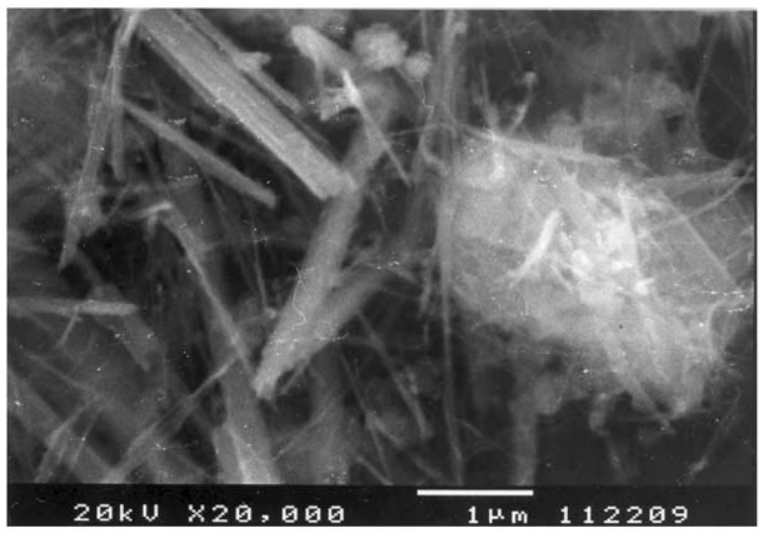

$3(b-5)$

Fig. 3. (Continued).

\section{5. $\mathrm{Mn} /$ Ce catalyst stability}

The stability of the solid catalysts has been found as dependent on the pollutant matrix contained in the effluents; for instance, high metal leaching was observed for $\mathrm{Mn} / \mathrm{Ce}$ when applied in the oxidation of polyvinyl alcohol [18] contrarily to the high stability of this catalyst found in the treatment of formaldehyde effluents [9]. Therefore, it is important to evaluate the $\mathrm{Mn} / \mathrm{Ce}$ catalyst stability for acrylic acid.

\subsubsection{Carbon adsorption}

The carbon adsorption by the $\mathrm{Mn} / \mathrm{Ce} 70 / 30$ catalyst was evaluated after the recovery of the catalyst at the end of the experiment. A low content of $0.095 \%$ (w/w) C was found, which corresponds to $2.85 \mathrm{ppm}$ of carbon in the $3 \mathrm{~g}$ of catalyst charged in the reactor; therefore, from the initial solution with $500 \mathrm{ppm}$ of TOC, approximately $0.57 \%(\mathrm{w} / \mathrm{w})$ $\mathrm{C}$ was adsorbed. Chen et al. [13] reported that a $\mathrm{Mn} / \mathrm{Ce}$ $60 / 40$ catalyst (similar to the one used in our study) is the most effective in terms of resistance to carbon deposition, since high manganese content, high surface area and high oxidation state are related with this catalyst. Hussain et al. [19] developed a new potassium-doped $\mathrm{Mn}-\mathrm{Ce}-\mathrm{O}$ with the aim to improve the catalyst in the phenol oxidation and to reduce the carbon adsorption found in previous studies as responsible for catalyst deactivation [10]. In fact, the results obtained under the present study (C: $0.095 \%$, w/w) are significantly lower (seven times) than the ones obtained by those authors with the K-promoted catalyst (C: $0.7 \%$, w/w). Platinum was also used as promoter for the $\mathrm{Mn} / \mathrm{Ce}$ stability [20], but higher values of deposited carbon (near $200 \mathrm{ppm}$ ) were found when compared with the ones obtained in this work. We believe that phenol reactions make propitious the formation of polymeric compounds at the catalyst surface blocking the active sites. For the acrylic acid oxidation this shortcoming was not detected by elemental analysis and the $\mathrm{Mn} / \mathrm{Ce}$ revealed to be stable in terms of carbon adsorption.

\subsubsection{Leaching of Mn to the liquid phase}

The stability of the $\mathrm{Mn} / \mathrm{Ce}$ catalysts was also analyzed in terms of the Mn metal leached to the liquid phase. Concerning $\mathrm{Mn} / \mathrm{Ce} 70 / 30,1.697 \times 10^{-3} \mathrm{~g} / \mathrm{l}$ of leached Mn was detected after $120 \mathrm{~min}$, which corresponds to $0.06 \%$ of the initial Mn concentration $(2.87 \mathrm{~g} / \mathrm{l})$, while a non-detectable content for $\mathrm{Mn} / \mathrm{Ce} 22 / 78$ was found $\left(<0.002 \times 10^{-3} \mathrm{~g} / \mathrm{l}\right)$. These results indicate that the $\mathrm{Mn} / \mathrm{Ce}$ catalyst presents high stability. Since the elution of Mn from the composite oxide catalyst practically did not occur, the effluent after the 
wet oxidation process is free from contamination by metal ions and can be securely released to the environment without a secondary treatment for metal separation. Therefore, the good activity of the $\mathrm{Mn} / \mathrm{Ce}$ catalyst referred above is strengthened by its high stability in terms of leaching as well as of low carbon adsorption.

\section{6. $\mathrm{Mn} /$ Ce micromorphology analysis}

\subsubsection{Scanning electron microscopy (SEM)}

SEM photographs of $\mathrm{Mn} / \mathrm{Ce} 70 / 30$ are presented in Fig. 3(a) for fresh catalyst and 3(b) for used catalyst after reaction. Different scales/magnifications were examined $(100 \times ; 500 \times ; 1500 \times ; 3500 \times ; 20,000 \times)$ and interesting textures and morphologies can be visualized. For magnification $100 \times$ the differences observed between the fresh and used catalysts (Fig. 3(a-1) and (b-1)) seem to be not very significant. However, a higher magnification (Fig. 3(a-2) and (b-2)) shows polished surfaces for the used catalyst while the fresh one seems to have more rough surface with small irregularly bulges. Moreover, it is interesting to note that in Fig. 3(b-2) small filaments are already observed in some particles of the used catalyst (inside circles). The magnification to $1500 \times$ in Fig. 3(b-3) clearly reveals the formation of a filament mesh that covers entire particles, not observed in the fresh catalyst (Fig. 3(a-3)). Fig. 3(b-4) $(3500 \times)$ shows that these filaments seem to be present in high quantity as well as various bright points are observed. Fig. 3(b-5) $(20,000 \times)$ clearly shows one of these points which is constituted by embroiled agglomerated filaments. Taking into account the scales referred in the figures, it can be concluded that such whiskers have different lengths up to approximately $10 \mu \mathrm{m}$. These whiskers that were formed under the CWO process with the $\mathrm{Mn} / \mathrm{Ce}$ catalyst were not yet referred in the literature at our knowledge. It is then our belief that these observations can be quite important for the commercial development of this catalyst. In this context it is important to know the constitution of these filaments.

Moulijn et al. [21] refer the formation of filaments due to carbon in catalysed reactions of hydrocarbons, which are decomposed at the metal surface of small crystallites. Afterwards the carbon diffuses through the metal forming a carbon nanotube between the support and the crystallite. However, taking into account the elemental analysis presented above, which revealed a low carbon quantity in the catalyst, it is not likely that in our case those filaments can be constituted by carbon. Therefore, transmission electron microscopy, energy-dispersive X-ray spectroscopy (EDXS) and selected-area electron-diffraction patterns (SAED) analyses were carried out in order to identify such filaments.

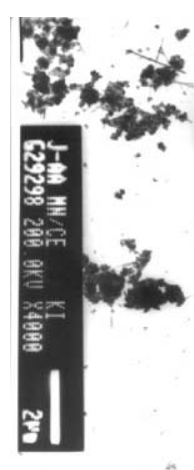

(a)

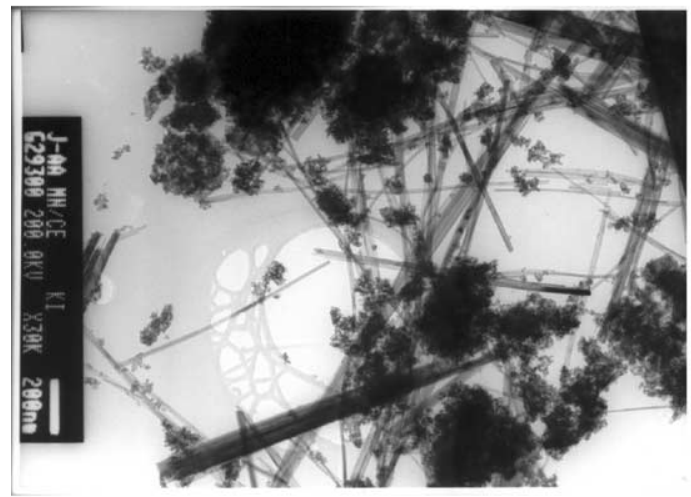

(c)

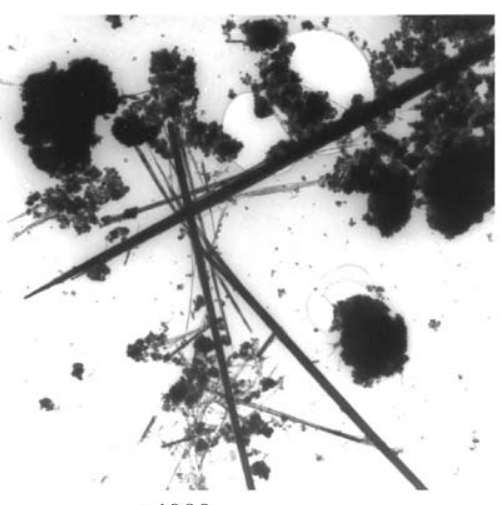

$\times 4000$

$\times 30 \mathrm{~K}$

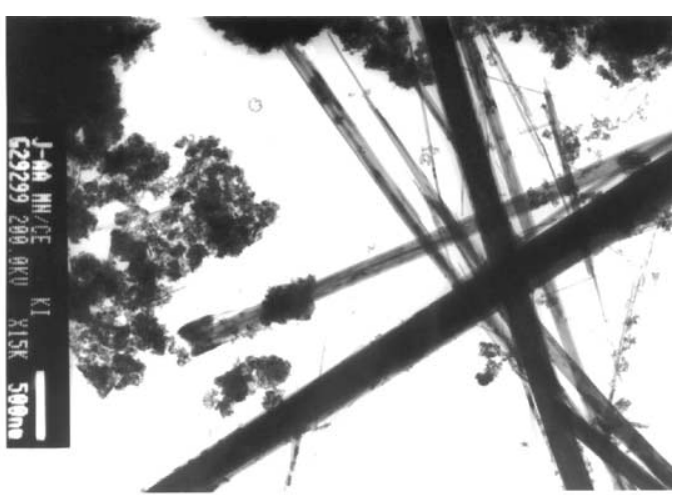

(b)

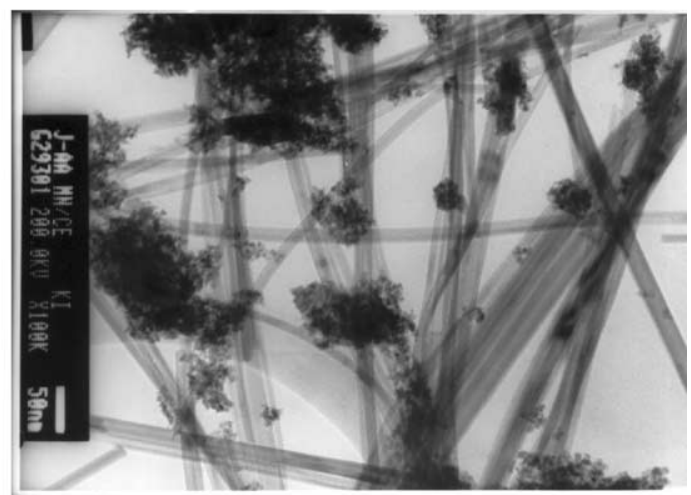

(d)

$\times 100 \mathrm{~K}$

Fig. 4. TEM micrograph of the Mn/Ce 70/30 catalyst after reaction at $200{ }^{\circ} \mathrm{C}$ and 15 bar oxygen partial pressure, for different scales/magnifications: (a) $4000 \times$; (b) $15,000 \times$; (c) $30,000 \times$; (d) $100,000 \times$. 
Sample J-AA, fine crystalline

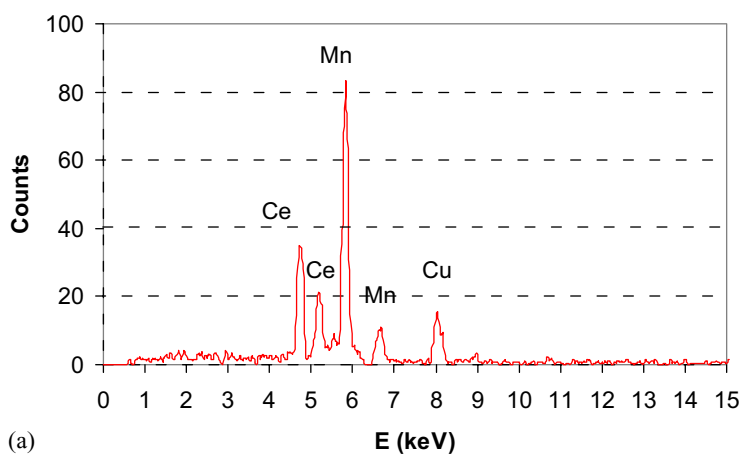

Sample J-AA, whisker

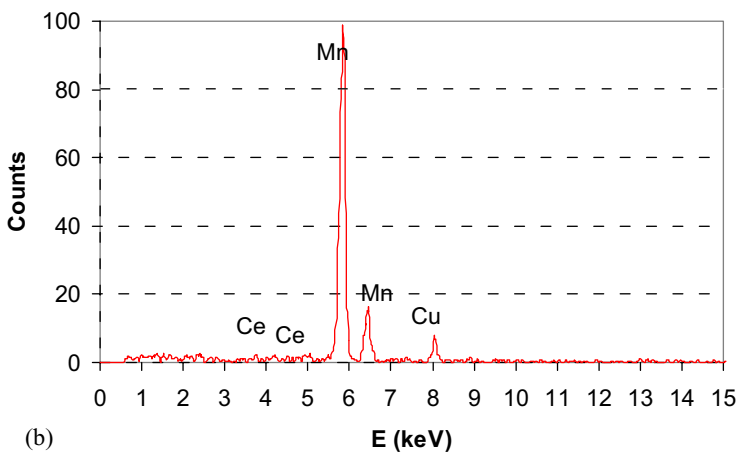

Fig. 5. EDXS analysis of the $\mathrm{Mn} / \mathrm{Ce} 70 / 30$ catalyst after reaction at $200^{\circ} \mathrm{C}$ and 15 bar oxygen partial pressure: (a) polycrystalline material; (b) whiskers.

3.6.2. Transmission electron microscopy (TEM), energy-dispersive $X$-ray spectroscopy (EDXS) and selected-area electron-diffraction patterns (SAED)

Fig. 4(a-d) correspond to the TEM photographs obtained at magnification of $4000 \times, 15,000 \times, 30,000 \times$ and $100,000 \times$, respectively. The same whiskers observed by SEM are now clearly showed with the TEM analysis. Moreover, particles of polycrystalline material can also be observed. In Fig. 4(a) the long whiskers present a shape similar with a needle: larger in the middle and narrow in the end. In Fig. 4(b) different whiskers with width up to $0.5 \mu \mathrm{m}$ can be observed. For high magnification photographs (Fig. 4(c) and (d)) the whiskers look flattened and very thin.

In order to analyze the metal constitution of the polycrystalline material as well as the one of the whiskers formed after the reaction, EDXS analysis were carried out and the results of Fig. 5 were obtained. In the polycrystalline material manganese and cerium were detected (Fig. 5(a)) while in the whiskers only Mn was found in EDXS spectra (Fig. 5(b)).
The analysis of the phases of $\mathrm{Mn}$ and Ce was performed by the interpretation of the SAED patterns that are shown in Fig. 6(a) for the polycrystalline material and in Fig. 6(b-d) for the whiskers. In the diffraction pattern of fine polycrystalline material, containing Ce (as seen in EDXS spectra), few diffuse rings can be observed. Normally, measuring only the d-values of these diffuse rings is not enough to determine which phase is present. However, in Fig. 7(a) the calculated (simulated) pattern for cubic $\mathrm{CeO}_{2}$ is compared with the experimental SAED pattern observed in Fig. 6(a). One can see that they agree very well, so we can conclude that the polycrystalline material is composed of cubic cerium.

On the other hand, SAED patterns of the whiskers can be indexed (Fig. 7(b)) as $\beta-\mathrm{MnO}_{2}$ (Pyrolusite) by comparing with the correspondent simulated pattern represented in Fig. 8(a). The same pattern could be also indexed as $\mathrm{MnOOH}$ (the simulated pattern in Fig. 8(b)) but in this case there should be also visible spots with larger d-values.

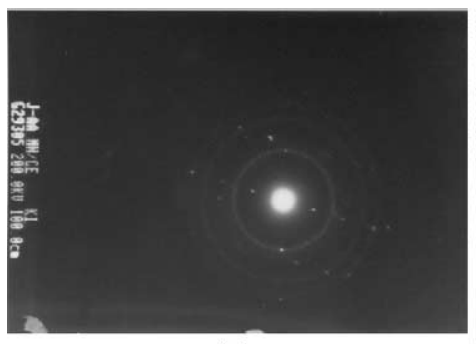

(a)

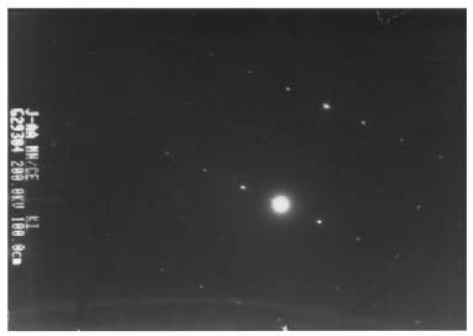

(c)

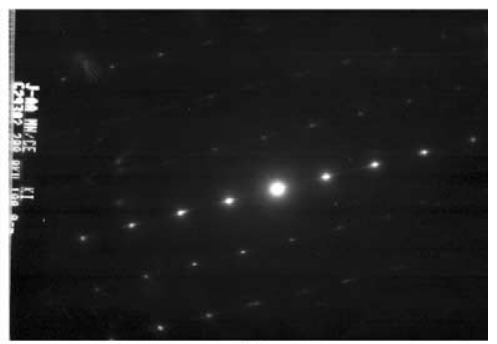

(b)

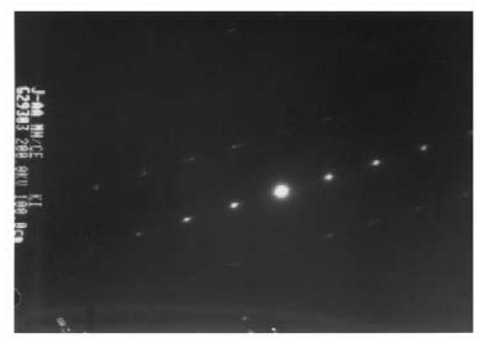

(d)

Fig. 6. Selected-area electron-diffraction (SAED) patterns: (a) polycrystalline material; (b)-(d) whiskers. 


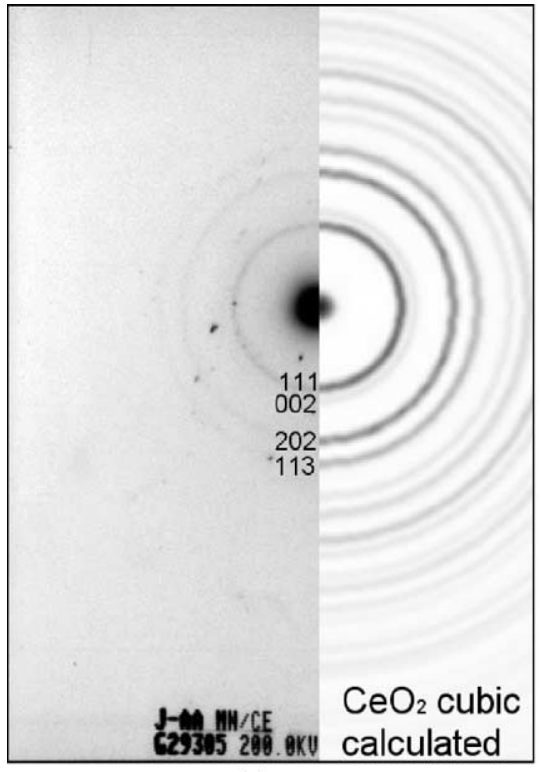

(a)

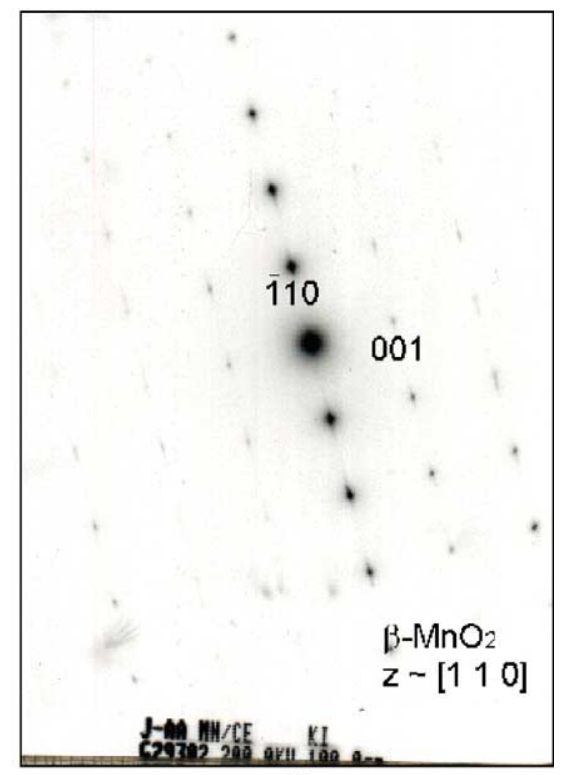

(b)

Fig. 7. Interpretation of the SAED patterns for (a) the polycrystalline material; (b) whiskers.

Crystal : mno2 /Acc. voltage $[\mathrm{kv}]: 200 /$ Camera length $[\mathrm{mm}]: 1022$

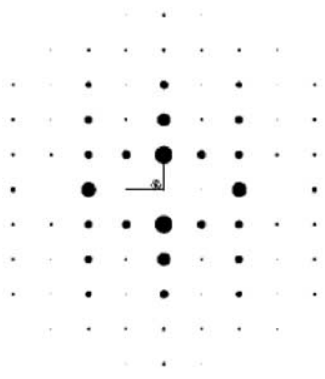

(a) $\mathrm{g} 1:(-1,1,0) / \mathrm{g} 2:(0,0,1) /$ zone axis $:[1,1,0]$
Crystal : mnooh /Acc. voltage $[\mathrm{kv}]:$ 200/Camera length [mm] : 863

Fig. 8. Simulated electron diffraction pattern (SAED) for (a) $\beta-\mathrm{MnO}_{2}$; (b) $\mathrm{MnOOH}$.

Therefore, it is more probable that these whiskers are of $\beta-\mathrm{MnO}_{2}$.

In the literature several authors [22-24] have been developing methods for preparation of $\mathrm{MnOOH}$ and $\beta-\mathrm{MnO}_{2}$ whiskers because they gained a considerable importance in many technological applications. These preparation methods are based in a hydrothermal procedure by mixing distilled deionized water, a Mn precursor and other compound as CTAB-cetyltrimethylammonium bromide [22] or TAH-tetraethylammonium hydroxide [23]. The CWO reaction process occurs in similar operating conditions and this fact can be the cause of the formation of such whiskers. In fact, Sun et al. [22], who obtained $\mathrm{MnOOH}$ and $\beta-\mathrm{MnO}_{2}$, showed in their paper very similar TEM images with the ones presented in Fig. 4(a-d). On the other hand Sharma and Whittingham [23] as well as Kanasaku et al. [25] showed a SEM image similar with Fig. 3(b-5) where several whiskers were observed. Thus, the analysis performed in this work and the results found in the literature seem to be consistent, indicating that after the reaction with the catalyst $\mathrm{Mn} / \mathrm{Ce} 70 / 30$ the whiskers formed are of $\beta-\mathrm{MnO}_{2}$ and/or $\mathrm{MnOOH}$.

Therefore, in the present work a step forward in the research of an active, stable and economic catalyst for the CWO process was carried out and we believe that more studies can lead to the $\mathrm{Mn} / \mathrm{Ce}$ catalyst commercialization since the efficiency of this catalyst for effluents containing acrylic acid was strongly highlighted with our results.

\section{Conclusions}

Our catalytic results point out $\mathrm{Mn} / \mathrm{Ce} 70 / 30$ to be an important catalyst for reduction of the environmental impact 
concerning effluents containing acrylic acid. This catalyst presents high selectivity for oxidation of acrylic acid as well as for all the reaction intermediates compounds, since $94.1 \%$ in TOC reduction was obtained in $30 \mathrm{~min}$ and $97.7 \%$ in $120 \mathrm{~min}$. The combination of high molar percentages of manganese with cerium is an important key factor in the high activity of the $\mathrm{Mn} / \mathrm{Ce}$ composite catalyst, since for $\mathrm{MnO}$ low initial reaction rates were found and poor manganese contents in $\mathrm{Mn} / \mathrm{Ce}$ catalysts leads to the formation of non-oxidizable compounds (13\% of the initial TOC). $\mathrm{CeO}$ alone and $\mathrm{Co} / \mathrm{Ce}$ did not show high activity for TOC oxidation probably due to the formation of acetic acid, the major reaction intermediate compound that was identified in this case, which was not able to be further decomposed by these catalysts. $\mathrm{Ag} / \mathrm{Ce}$ shows high activity for the initial reaction; however a not oxidizable fraction of TOC $(15 \%)$ was detected.

The $\mathrm{Mn} / \mathrm{Ce}$ catalyst showed high stability regarding carbon adsorption and leaching of the metals to the liquid phase. Formation of whiskers was observed in the used catalyst by both SEM photographs and TEM micrograph. The EDXS leads to conclude that these whiskers are constituted by manganese, in the form of $\beta-\mathrm{MnO}_{2}$ and/or $\mathrm{MnOOH}$, being however the last one less probable. Therefore, our experiments revealed that the $\mathrm{Mn} / \mathrm{Ce} 70 / 30$ catalyst is a crucial driver to improve the carbon removal of acrylic acid in contaminated wastewaters, being then able to preserve environmental quality.

\section{Acknowledgements}

The Fundação para a Ciência e Tecnologia, Portugal, is gratefully acknowledged for the financial support. The authors want to thank Dr. Goran Drazic, Department for Nanostructured Materials, "J. Stefan" Institute, Ljubljana, Slovenia, for the great technical support.

\section{References}

[1] F. Luck, Catal. Today 53 (1999) 81.

[2] S.T. Kolaczkowski, P. Plucinski, F.J. Beltran, F.J. Rivas, D.B. McLurgh, Chem. Eng. J. 73 (1999) 143.

[3] V.S. Mishra, V.V. Mahajani, J.B. Joshi, Ind. Eng. Chem. Res. 34 (1995) 2.

[4] R.V. Shende, J. Levec, Ind. Eng. Chem. Res. 39 (2000) 40.

[5] Fluka Chemie GmbH and Riedel-deHaën, Scientific Research, Madrid, 2003, p. 46.

[6] Y.I. Matatov-Meytal, M. Sheintuch, Ind. Eng. Chem. Res. 37 (1998) 309.

[7] S. Imamura, Ind. Eng. Chem. Res. 38 (1999) 1743.

[8] L. Olivero, J. Barbier, D. Duprez, A. Guerrero-Ruiz, B. Bachiller-Baeza, I. Rodríguez-Ramos, Appl. Catal. B 25 (2000) 267.

[9] A.M.T. Silva, I. Castelo-Branco, R.M. Quinta-Ferreira, J. Levec, Chem. Eng. Sci. 58 (2003) 963.

[10] S. Hamoudi, K. Belkacemi, F. Larachi, Chem. Eng. Sci. 54 (1999) 3569.

[11] S. Imamura, A. Doi, S. Ishida, Ind. Eng. Chem. Prod. Res. Dev. 24 (1985) 75.

[12] S. Imamura, I. Fukuda, S. Ishida, Ind. Eng. Chem. Res. 27 (1988) 718.

[13] H. Chen, A. Sayari, A. Adnot, F. Larachi, Appl. Catal. B 32 (2001) 195.

[14] S. Imamura, M. Nakamura, N. Kawabata, J. Yoshida, S. Ishida, Ind. Eng. Chem. Prod. Res. Dev. 25 (1986) 34.

[15] W. Zhu, Y. Bin, Z. Li, Z. Jiang, T. Yin, Wat. Res. 36 (2002) 1947.

[16] S.H. Lin, S.J. Ho, Appl. Catal. B 9 (1996) 133.

[17] S. Imamura, Y. Okumura, T. Nishio, K. Utani, Y. Matsumura, Ind. Eng. Chem. Res. 37 (1998) 1136.

[18] A.M.T. Silva, R.N.P. Vaz, R.M. Quinta-Ferreira, J. Levec, Can. J. Chem. Eng. 81 (2003) 566.

[19] S.T. Hussain, A. Sayari, F. Larachi, Appl. Catal. B 34 (2001) 1.

[20] S. Hamoudi, F. Larachi, G. Cerrella, M. Cassanello, Ind. Eng. Chem. Res. 37 (1998) 3561.

[21] J.A. Moulijn, A.E. van Diepen, F. Kapteijn, Appl. Catal. A 212 (2001) 3.

[22] X. Sun, C. Ma, Y. Wang, H. Li, Inorg. Chem. Commun. 5 (2002) 747.

[23] P.K. Sharma, M.S. Whittingham, Mater. Lett. 48 (2001) 319.

[24] S. Ardizzone, C.L. Bianchi, D. Tirelli, Coll. Surf. A 134 (1998) 305.

[25] T. Kanasaku, K. Amezawa, N. Yamamoto, Solid State Ionics 133 (2000) 51. 